Revista Iberoamericana, Vol. LXXIV, Núm. 222, Enero-Marzo 2008, 1-

\title{
LA “RECONQUISTA” DE AMÉRICA EN LA HISTORIA ANTIGUA DE MÉXICO DE FRANCISCO JAVIER CLAVIJERO
}

\author{
POR \\ SERgio Rivera-Ayala \\ Wayne State University
}

Durante el siglo Ilustrado, el espacio americano, lo mismo que el resto del mundo no occidental, se pone nuevamente en disputa en los principales escenarios del poder europeo, lo que Antonello Gerbi ha denominado "la disputa del Nuevo Mundo". El proyecto expansionista que emprenden tanto la corona española como las nuevas potencias de Occidente, el “corazón de Europa” como llamaría Hegel al grupo de naciones constituidas por Inglaterra, Francia y Alemania, consistía, entre otras cosas, en hacer uso de la historia natural como lenguaje científico, convirtiéndose en una herramienta eficaz para acceder al conocimiento de la naturaleza y revelar las “verdades” del orden natural de las cosas. Esta renovación de la historia natural se da conjuntamente con la exploración tierra adentro que Europa emprende en los territorios colonizados o en proceso de colonización.

Para esta época, las naciones del corazón de Europa habían ya desplazado a España y Portugal como potencias colonizadoras, adquiriendo una fuerte conciencia de que el estado de civilización al que habían llegado-ciencia, tecnología, arte-era muy superior al del resto del mundo. Esta visión desarrollista da lugar a que se rearticule un nuevo discurso expansionista colonial dirigido desde la Europa del norte, lugar del locus cultural y centro del "proceso civilizador", pues es ahí desde donde se dan las pautas a seguir para justificar los proyectos de exploración hacia la periferia del orbe occidental. ${ }^{1}$ Esta noción de “civilización” le permite al europeo definirse como un sujeto productor de nuevos discursos, con los cuales articula todo un conocimiento científico sobre el resto del mundo para luego utilizarlo para marcar las diferencias "naturales" que lo separan de los que él considera naciones "bárbaras” e “inmaduras”. Luis Villoro señala que la Europa ilustrada "tiene por fin una pauta infalible y universal para valorarlo todo, [que es] válida no sólo en el terreno sobrenatural-como lo era la revelación-sino en todos los campos: la razón. Y por ese yugo deberá pasar de nuevo América” (113).

\footnotetext{
1 Si bien este concepto evolucionista de “civilización”, que Norbert Elias (1978) llama “civilizing process” -transformación del concepto aristocrático "policía”-, fue utilizado por las emergentes clases medias en su lucha social por ganar espacios políticos que la aristocracia había sustentado por siglos, el poder político que dicho concepto llevaba implícito también sirvió como modelo discursivo de supremacía para imponerse sobre el resto de las naciones del orbe no occidental.
} 
Parte de esta modernidad dieciochesca es la nueva visión que se tiene del espacio, ${ }^{2}$ claramente reflejada en la preocupación europea por conocer y controlar más a fondo los territorios que estaban bajo su dominio o en disputa, todo ello con el fin de obtener un mejor conocimiento de las riquezas de sus posesiones, y así tener un mayor acceso a ellas para su eficiente explotación. Esta nueva manera de ver el espacio americano viene a reinventar nuevamente su imagen, ya no solamente como mero espacio geográfico-definido así desde el siglo XVI-, sino como una naturaleza degradada, ya por la influencia del clima o por la incapacidad de sus habitantes para transformar el ambiente en que vivían, y crear sociedades con gobiernos e instituciones avanzados como en la Europa del norte.

La ofensiva política, histórica y económica que se origina desde los escritorios de los centros del poder europeo, y que Mary Louise Pratt (1992) llama la "nueva conciencia planetaria”, crea su contraparte en los virreinatos americanos, entre las sociedades criollas locales que impugnan, dentro y fuera del territorio americano, la manera negativa en que los extranjeros veían y describían las tierras que los habían visto nacer. En el presente artículo analizaré estas dos maneras de ver el espacio americano. Por un lado, la nueva forma de ver el espacio americano que la "visión" planetaria impone, enmarcada dentro de la corriente enciclopédica Ilustrada que se va imponiendo en los círculos del saber de las nuevas potencias europeas, en su intento por desplazar al imperio español del continente americano y disputarle el poder de explotarlo y colonizarlo. Las nuevas regulaciones que la corona española impone a sus colonias americanas, a través de las reformas borbónicas, corren paralelamente a este nuevo discurso de la filosofía natural, el cual describía al continente americano y sus pobladores como "degenerados" e "impotentes” y, por lo tanto, inferiores a Europa. Por el otro lado, analizaré la respuesta que la clase letrada novohispana produce para contrarrestar y refutar el nuevo discurso colonialista, particularmente en la Historia antigua de México, del jesuita criollo Francisco Javier Clavijero, quien objeta desde su exilio en Bolonia la manera errónea y unilateral en que los europeos ilustrados percibían tanto al territorio americano como a sus habitantes.

Asimismo, en la Nueva España como en los demás virreinatos, se producen una serie de respuestas que dan paso a una expresión de identidad nacional que impugna lo que los propios criollos llaman las mentiras europeas del momento. Esta disputa sobre el espacio y el cuerpo americanos se da en el preciso momento en el que la sociedad criolla se encontraba en una etapa de madurez económica, cultural y política, la cual no solamente le facilita la búsqueda de respuestas contra ese nuevo discurso expansionista europeo, sino que también le ayuda a crear e inventarse una imagen propia, a través de la cual el anhelado sueño criollo, de ser los dueños y señores de esos territorios, va a ser alcanzado más tarde con la independencia de las naciones americanas durante el siglo siguiente.

Para el virreinato de la Nueva España, el siglo Ilustrado se presentaba como un periodo de transición y de cambios drásticos, manifestado en un desequilibrio en todos los niveles debido al gran desarrollo económico impulsado por las reformas borbónicas. Sin embargo esta bonanza económica trae un reparto desigual en la distribución de las ganancias, agravando aun más la desigualdad social ya existente, y creando, a la vez, un mayor

\footnotetext{
2 Johannes Fabian (1983) llama la atención sobre este visualismo que existe en este tipo de interacción comunicativa.
} 
resentimiento entre la clase criolla, que había salido afectada por las reformas, lo cual hizo recordarles su posición subalterna dentro del sistema español (Florescano 578-583).

A partir de la década de 1760, y a diferencia de lo que había sucedido en el siglo anterior, el estado español asume una política más cercana y agresiva hacia sus colonias americanas, para emprender así lo que David Brading llamaría “la reconquista de América” (467-491). Según Enrique Florescano, las reformas borbónicas se dirigían exactamente a "recuperar los hilos que, con independencia de la metrópoli, movían desde hacía más de un siglo los mecanismos económicos, políticos y administrativos de la colonia; colocarlos bajo la dirección y vigilancia de hombres adeptos a la metrópoli, y hacerlos servir a ésta por sobre cualquier otra consideración” (492). En efecto, la nueva orientación del llamado “despotismo ilustrado” se concentra en readaptar la administración del espacio colonial a los intereses de la corona española, siempre siguiendo los nuevos postulados económicos que las nuevas potencias europeas estaban practicando en sus posesiones de Asia y África, con el fin de instaurar los instrumentos necesarios para fortalecer la explotación de los recursos, así como el reestablecimiento del comercio con la península ibérica. Por otra parte, esta reconquista que las reformas borbónicas proyectan alcanzar radica en ya no solamente el control del indígena, ${ }^{3}$ sino que también estaban orientadas a eliminar muchos de los privilegios que había acumulado en los siglos anteriores, la otra clase social nativa de América, los criollos.

El golpe seguido contra la sociedad criolla sería la expulsión de los jesuitas de los territorios americanos en 1767. El reconocimiento social que gozaba esta orden religiosa en la Nueva España tenía una larga historia, pues desde su llegada a tierras americanas en 1572 había desempeñado un papel diametralmente opuesto a lo que hacía la Compañía en Europa. "De un golpe -señala Tanck de Estrada- la Nueva España perdió el grupo de educadores de mayor número, talento y prestigio" (42). Su peso intelectual había determinado el despertar criollo, pues habían sido maestros, mentores, voceros y forjadores de su nacionalidad desde tiempos tempranos de la colonia, inclinándose desde el siglo xvıı por una tendencia de pensamiento cristiano sincretista, lo cual les permitió apropiarse del pensamiento religioso indígena, y establecer aspectos paralelos entre ellos a fin de cristianizar el paganismo americano. ${ }^{4}$ La expulsión generó sublevaciones en diferentes ciudades en donde los jesuitas tenían una presencia significativa: Pátzcuaro, San Luis Potosí, Guanajuato, San Luis de la Paz, Uruapan. Reveladora fue también la dura reacción que el gobierno colonial

\footnotetext{
${ }^{3}$ La corona también implementó, siguiendo los consejos de Campillo y Cossío delineados en su manuscrito de 1743, publicado en 1789, políticas para obtener un mejor control sobre la población indígena, como fue la promoción del uso del castellano, y así acabó con toda una política seguida desde el siglo xvi, la cual había establecido la República de Indios, en donde los indígenas pudieran preservar su propia cultura y tradiciones apartada de la República de Españoles. Esta política también va a afectar indirectamente a los criollos, quienes habían utilizado sus conocimientos de las lenguas y culturas indígenas para obtener ciertos cargos. Con estas políticas de castellanización ya no iba a ser necesario el conocimiento de las lenguas indígenas para ocupar estos puestos $\mathrm{y}$, por tanto, la entrada de peninsulares a estos espacios, considerados como exclusivos para los clérigos criollos, causaría un revuelo entre la sociedad novohispana (Tanck de Estrada 48-56).

${ }^{4}$ Por ejemplo, Edmundo O’Gorman (1986) ve una estrecha relación entre la Contrarreforma y el culto a la virgen de Guadalupe.
} 
toma ante tales rebeliones, pues el visitador José de Gálvez, con la ayuda de su inspector general de tropas, Juan de Villalba, no titubea en hacer uso de su autoridad para contrarrestar el descontento popular (Florescano 467-68). ${ }^{5}$

Por otro lado, mientras los pobladores y territorios americanos estaban siendo embestidos por las reformas borbónicas, en los círculos científicos europeos de la Europa del Norte se estaba debatiendo la supuesta inferioridad física y antropológica de América. Con la ayuda del discurso científico de la época, el continente americano se describía ante el público lector europeo como un mundo nuevo, todavía inmaduro y con una naturaleza degradada y desatendida por la misma inferioridad e incapacidad de sus habitantes para transformar el terreno que poseían. La atención de los filósofos europeos no estaba suscrita a lo meramente científico, pues estaban en juego los intereses de las principales potencias europeas que buscaban sustituir a España en el continente americano, para luego quedarse con las riquezas naturales que sus centros manufactureros tanto ansiaban.

Para el siglo xviII, Europa adquiere lo que Mary Louise Pratt ha llamado una nueva “conciencia planetaria”, entendida como una expansión y exploración al interior de los continentes, la cual también va a alterar las maneras en que el europeo se percibía a sí mismo, y el lugar que ocupaba en el mundo como ente civilizador, convirtiéndose en la base fundamental en la construcción del eurocentrismo moderno (15). Dentro de esta odisea expedicionaria la historia natural funcionaría como una herramienta científica con la que se iba a explorar, clasificar, y acceder al conocimiento de los territorios y pueblos no europeos que se encontraban bajo las disputas imperiales. ${ }^{6}$ El sistema de clasificación creado por Linneo es uno de los frutos de esta "conciencia planetaria”, pues su principio estandarizador que se iba a aplicar al mundo natural se fue imponiendo al resto del planeta, anulando la validez de otros sistemas clasificatorios nativos ya existentes en otras latitudes fuera de Europa. ${ }^{7}$ Además, los naturalistas de la Ilustración no dudan en utilizar los conceptos de

\footnotetext{
${ }^{5}$ El inspector general de tropas, don Juan de Villalba, muy pronto pasó a ser uno de los personajes más odiados en la Nueva España, y se convirtió en el blanco de muchos textos satíricos anónimos de la época, como en el popular baile del chuchumbé, que apareció por vez primera en las calles del puerto de Veracruz en el año de 1767, para luego extenderse a varios puntos del virreinato (Rivera-Ayala 2000). Véase también Miranda y González Casanova (1953).

${ }^{6}$ Ejemplo de ello es la exploración internacional de 1735, comandada por franceses, la cual tenía como objetivo poner fin al debate de sí la tierra era más ancha por el ecuador o por los polos. Para esto salió una expedición al polo norte y otra al ecuador. Véase Pratt (1992), especialmente el capítulo 2. Suzanne Zantop (1993) señala que este discurso derrogatorio sobre América que se da en esta época es el resultado de una crisis de identidad europea que trata de establecerse como la autoridad patriarcal en relación con la Otredad, interna y externa: "[the] popular (mis)conceptions about otherness [...] constructed them into a seemly coherent American reality that not only explained and atoned for the history of conquest but also provided the parameters for a new identity of the European male-that of 'natural man' as 'natural colonizer'” (303).

${ }^{7}$ El sistema de Linneo encontró sus críticos dentro de las comunidades científicas. En Europa, según Londa Schiebinger, Buffon fue uno de sus más fieros detractores pues consideraba el sistema de Linneo como demasiado abstracto y artificial (28). En la Nueva España también encontró oposición, esta vez entre los naturalistas criollos. José Antonio Alzate señalaba que todos los jardines botánicos americanos deberían utilizar el sistema clasificatorio indígena ya
} 
género y especie para clasificar jerárquicamente las plantas y animales, y la aplicación se extendería al género humano, con enormes ramificaciones en la ideología racista de siglos posteriores.

El Nuevo Mundo no sólo se convirtió en el terreno propicio para ensayar el nuevo lenguaje científico, que tanto las ambiciones imperiales como los apetitos económicos del Viejo Mundo habían creado, sino que también se convertiría en un campo privilegiado para oponer los dos sistemas imperiales reinantes: por un lado, el antiguo y caduco sistema español y, por otro, los modernos e imperantes de las nuevas potencias europeas, Francia, Inglaterra y Alemania. A través de las herramientas de la historia natural, los ilustrados europeos se propusieron esclarecer y corregir los errores que, según ellos, habían cometido los cronistas e historiadores españoles del siglo xvı, quienes sin ningún método científico convincente habían descrito la naturaleza y los pueblos americanos. Las fuentes historiográficas sobre América dejadas por los conquistadores y misioneros españoles, así como por cronistas indígenas, son cotejadas con la nueva experiencia que viajeros y filósofos ilustrados contemporáneos habían acumulado al explorar y/o estudiar el nuevo continente y sus habitantes. Como señala Jorge Cañizares-Esguerra (2001), la Europa Ilustrada crea así un "nuevo arte de leer" e interpretar la historia del Nuevo Mundo que se basa en un escepticismo hacia la historiografía renacentista, mezclado con reminiscencias de la Leyenda Negra, y una taxonomía científica, sin dejar a un lado la antigua asociación que la tradición europea le daba al clima como un determinante del genio humano.

En el año de 1768 apareció publicada en Berlín Recherches philosophiques sur les Américains, una de las obras más hostiles contra el continente americano que la teoría determinista ilustrada vendría a producir. Dicha tesis que -en palabras de Francisco Javier Clavijero- "la turba de escritores modernos" se regocijaba en debatir, argumentaba la supuesta inferioridad de la naturaleza americana. Su autor, el abate holandés Corneille de Pauw, quien se jactaba de haber trabajado por diez años en dicha obra, no solamente se había valido de la tesis del conde de Buffon que postulaba el estado de imperfección en la que se encontraba el "nuevo" continente debido a su inmadurez. De Pauw lleva esta tesis a los extremos al sostener que, más que estar marcado por imperfección, el Nuevo Mundo había degenerado a tal grado que la fragilidad y descomposición de su naturaleza era inferior en su totalidad con respecto al Viejo Mundo, pues el estado de decadencia en el que se encontraba estaba también reflejado en la inferioridad de sus plantas y animales, así como en la constitución física del habitante americano. A lo largo de Recherches philosophiques, De Pauw insiste en que la radical diferencia del viejo mundo con respecto al nuevo era la fuerza y el estado de civilización en que se encontraba el primero, en contraste con el abandono y estado salvaje en que se hallaba la naturaleza americana. El continente americano estaba en un estado tal de degeneración que no podía ofrecer el ambiente propicio para la generación de una sociedad culta y avanzada. Al vivir en un ambiente natural de decaimiento, los indígenas no podían evitar ser una raza envilecida, de cobardes, ociosos, y sin fuerza física, cuyo entorno los hacía incapaces de cualquier progreso intelectual. El hombre

que era mejor que el de Linneo, pues clasificaba las plantas sobre bases duales, de apariencia y propiedades. Gaceta de Literatura, 30 de diciembre de 1790. Véase Tanck de Estrada (1981), 91-94. 
americano era tan débil que, en una pelea, el hombre europeo más débil los podía derrotar con facilidad. Esta teoría determinista se sustentaba en el factor climático, el cual se creía había jugado un papel muy importante en el desarrollo de la naturaleza y los habitantes del globo terrestre: "it is without a doubt a great and terrible spectacle to see half the globe so thoroughly maltreated by Nature that everything in it was either degenerate or monstrous" (Gerbi 58).

El argumento principal de De Pauw, que muchos naturalistas europeos contemporáneos suyos compartían, se basaba en demostrar que la inferioridad del poblador americano era consecuencia de las condiciones ambientales en las que vivía. De la misma manera que Jean Bodin, De Pauw cree que la perfección del hombre sólo se podía dar dentro de la sociedad, bajo sus instituciones y sus leyes, pues de lo contrario, la sola naturaleza volvería al hombre a un estado silvestre e incapaz de cualquier progreso:

Man is thus nothing by himself; he owes what he is to society; the greatest Metaphsyscian, the greatest philosopher, if he were abandoned for ten years on the Isle of Fernandez, would come back transformed into a brute, dumb and imbecile, and would know nothing in the whole nature. (58)

Con esto, De Paw acaba con la noción del “buen salvaje” que los misioneros españoles habían creado durante el siglo xvi, quienes, en su intento por defender al habitante americano de los abusos y codicia de los conquistadores españoles, habían mirado las sociedades americanas bajo la tradición utópica de la Edad de Oro de la humanidad, como una edad de inocencia (Ainsa 1992). Si el clima tenía un efecto en la complexión y calidad de los hombres, entonces la gran diversidad de pueblos se explicaba por la misma diversidad de climas que había en el mundo. Estas teorías no eran nada nuevas, ya que sus orígenes se pueden trazar desde las teorías de los humores de Galeno y la medicina hipocrática, las cuales ya habían sido esquematizadas durante el siglo xvi por autores como Jean Bodin y Huarte de San Juan, entre otros (Noreña 1975).

Una de las características que constantemente se destacan del ambiente americano, y que se convierten en leitmotiv del discurso naturalista, es su supuesta humedad y frialdad. Para Buffon, el clima y la naturaleza de América no han permitido el desarrollo natural del hombre americano, ya que la misma frialdad era transmitida a este último, de manera que adquiría características propias de otras especies de sangre fría, convirtiéndolo en un ser incapaz de trasformar ese mismo ambiente en el que nacía. Esa imagen de impotencia y virilidad anómala que se asoma en las descripciones del hombre americano, cuyos vestigios masculinos, deformados por el clima en el que vive, lo convierten en un sujeto demasiado pasivo como para poder compararse y competir con la vigorosa e imperial masculinidad europea, debe también leerse dentro de los sistemas de clasificación y diferenciación que se estaban dando dentro del discurso científico Ilustrado, para ver cómo las leyes de la naturaleza se van adaptando a las relaciones del poder colonial con el fin de justificar la explotación de los pueblos y recursos naturales.

La teoría de los humores de la filosofía natural servirá de base principal para encontrar los rasgos particulares que demuestren la desigualdad entre el hombre europeo, establecido como la norma de humanidad masculina, y el no europeo, como ejemplo de la anormalidad 
humana. Ya Huarte de San Juan, en su libro Examen de ingenios, explicaba cómo el calor o frío influían en el desarrollo de los órganos sexuales de los niños dentro del vientre de la madre. Según Galeno, el cuerpo del hombre no era muy diferente al de la mujer, más que en la forma exteriorizada de sus órganos genitales, pues el útero y los ovarios tenían una compostura muy similar a la del miembro viril y los testículos, pero simplemente a la inversa y de una manera interna, ya que el calor tenía la propiedad de agrandar y hacer crecer las cosas, mientras que el frío las encogía o reducía (608-10).

Desde esta perspectiva de la teoría de los humores están delineadas las imágenes de América y sus habitantes que emanan del discurso científico europeo. El énfasis que se pone sobre la humedad y la frialdad de su ambiente, según lo afirman Buffon y otros que siguen sus señalamientos, no hace más que mostrar al americano como un ser con características más femeninas que masculinas. Los indígenas son hombres flojos, débiles, pobres de espíritu, y con una inhabilidad de transformar el ambiente en el que viven y, consecuentemente, de crear sociedades con instituciones y leyes similares a las que se habían formado en Europa. En otras palabras, estas mismas características climáticas habían creado los obstáculos para el desarrollo normal de las especies existentes en el Nuevo Mundo, reduciéndolas en número y tamaño, y confiriéndoles una incapacidad de reproducirse, lo cual forzosamente hacía que disminuyera el número de especies en el continente. Por tanto, el hombre americano habitaba un territorio ocioso e infértil, el cual no inspiraba a ningún apetito de dominación o posesión: "where having never subjugated either animals or the elements, not tamed the waters, nor governed the rivers, nor worked the earth, he was himself no more than an animal of the first order" (Gerbi 5).

Si bien Buffon insinúa que las condiciones estériles de la naturaleza hacían fútil la subyugación de la misma, también esa misma nulidad hace imposible que el hombre americano ejerciera un dominio sobre el mundo natural debido a su falta de fortaleza corporal y viril. Si la naturaleza americana había transmitido esas cualidades de frialdad y humedad al hombre americano, cualidades que, como ya lo he señalado, hacían también referencia a lo femenino dentro de la teoría de los humores, la filosofía natural intentaba fijar así la corporalidad del americano bajo rasgos femeniles, con lo cual se establecía esa diferencia corporal con respecto al hombre europeo bajo las categorías genéricas. Tal y como Huarte de San Juan había señalado acerca de la intervención del calor y/o la frialdad en el desarrollo de los órganos sexuales de los niños en el vientre de la madre, Buffon resalta la influencia del ambiente americano en el hombre al indicar que "The savage is feeble and small in his organs of generation; he has neither body hair nor beard, and no ardor for the female of his kind" (Gerbi 6; énfasis mío), de lo cual se colige que la frialdad y la humedad habían encogido los órganos sexuales del hombre o, quizás, a éste no se le habían desarrollado y/o exteriorizado como debían, de tal manera que su masculinidad estaba en duda, no solamente por la incapacidad innata que tenía de conquistar y dominar el mundo natural en que se encontraba, sino también por la hombría anómala reflejada, como en la falta de pelo y barba, y en la carencia de un deseo sexual por la mujer. ${ }^{8}$ En otras palabras, el control y dominio de la tierra y, por extensión, de la mujer, se establecen como características masculinas

${ }^{8}$ Similares comentarios hace el abate Raynal sobre el hombre americano, señalando su indiferencia hacia el sexo opuesto, lo cual le sugería una imperfección orgánica o inmadurez, muy acorde con las condiciones del resto del continente (Gerbi 47-48). 
europeas, ya que ambas son inexistentes -según Buffon- en el hombre americano. Para el filósofo francés, la distinción está hecha entre el "hombre-europeo-cultura” colonizador y el "hombre-americano-naturaleza” colonizado.

La misma falta de vello corporal y facial coloca al hombre americano dentro de lo corporal femenino, pues hace alusión a la ausencia de esos símbolos masculinos que la cultura occidental preciaba como parte integral de la imagen corporal del hombre. Nuevamente se hace referencia a esta privación de vello, especialmente el facial, pues representaba la carencia de un símbolo masculino de poder y supremacía, al cual Carl Linneo había aludido como algo que Dios había dado a los hombres como ornamento y para distinguirlos de las mujeres (Blunt 157). Voltaire también iba a señalar y relacionar esa imagen del americano sin barba, ya fijada en el discurso colonial europeo desde el siglo xvI, ${ }^{9}$ como una falta de masculinidad e indicio de su debilidad e inferioridad, pues según el filósofo francés, la historia había demostrado que ese tipo de gente (sin barba) no ofrecía resistencia alguna ante la embestida colonial europea. ${ }^{10} \mathrm{~A}$ través de estas posiciones antropológicas se puede notar cómo el siglo xviII de la Europa ilustrada articula un tipo de cuerpo que se va definiendo dentro de su propuesta discursiva de exploración planetaria cuyos rasgos estaban delineados bajo los parámetros de la masculinidad europea que se establecía como norma y con la cual se va clasificar y ordenar la humanidad entera.

Con la ayuda de la filosofía natural como herramienta científica, los centros del poder europeos conciben los territorios americanos como estados vírgenes y de naturaleza degradada, lo cual constituía una prueba palpable de la incapacidad e impotencia del hombre americano para transformar y explotar la naturaleza para su propio beneficio, y así crear sociedades civilizadas. De esta manera lo había señalado el deán de Alicante, Manuel Martí, en una carta escrita en latín en 1735, y dirigida a un joven interesado en realizar sus estudios en México. En su epístola, Martí califica el ambiente intelectual de la Nueva España como un "vasto desierto literario" en el cual no existían maestros, ni libros, ni bibliotecas, por lo que persuade al joven estudiante para que abandone su intento de trasladarse a la ciudad novohispana, y se dirija mejor a Roma.

Entre las respuestas que emanan de las plumas criollas se destaca la del Dr. Juan José de Eguiara y Eguren, profesor y rector de la Real y Pontificia Universidad de México, quien en su intento por impugnar y demostrar lo contrario a lo dicho por el deán de Alicante, se dedica a compilar la tradición intelectual novohispana, incluyendo a la indígena, dentro de una obra que se llamaría Bibliotheca Mexicana. El proyecto de Eguiara y Eguren buscaba ser una bibliografía comprensiva de la historia intelectual mexicana, organizada de una manera alfabética, de individuos y sus obras, abarcando desde la época prehispánica hasta el año de 1755. Sin embargo, la obra no pudo ser finalizada por el fallecimiento de su autor y sólo pudo salir a la luz el volumen que comprendía las secciones de la A a la C.

Puesto en marcha como estrategia, el cientificismo y enciclopedismo ilustrados les abre las puertas a los grupos intelectuales criollos para construir y debatir sus propios proyectos

\footnotetext{
${ }^{9}$ Desde el encuentro colombino, el europeo ve la ausencia de la barba en el cuerpo del americano como una desviación a la norma masculina europea. Véase mi libro Espacio, cuerpo y poder (2007).

10 Voltaire, haciendo una analogía, señala que los leones que existen en América son más pequeños que los del Viejo Mundo, y carecen de melena, además de ser cobardes (Gerbi 45).
} 
de nación que interpretaban el espacio novohispano y la historia intelectual acumulada e inventariada por ellos mismos, lo que Anthony Higgins (2000) ha nombrado el "archivo criollo”, como algo que habían heredado, tanto de los indígenas como de sus parientes más cercanos, los europeos. Es así como lo entiende el jesuita mexicano Francisco Javier Clavijero, a quien, desde su exilio “a más de dos mil trescientas leguas de su patria” le tocaría defender la historia y la cultura del suelo que lo vio nacer y reafirmar, al mismo tiempo, la imagen del imperio azteca como una civilización avanzada a la cual se podía comparar con las del viejo mundo.

Clavijero fue uno de los tantos jesuitas criollos que sufrió la política de expulsión de la Compañía de Jesús en el año de 1767, abandonando la Nueva España para embarcarse rumbo a Bolonia, Italia, en donde viviría el resto de su vida. Aunque Clavijero originalmente escribe su Historia antigua de México en español, es persuadido por unos literatos italianos que estaban interesados en leer su obra-según lo señala el propio autor-para que la tradujera al italiano (toscano) y para que la publicara en 1780. La obra consta de diez libros que cubren la historia prehispánica y la época de la conquista, así como de nueve disertaciones, en donde el autor se dedica a refutar directamente las diatribas de los naturalistas europeos ilustrados.

Clavijero escribe su Historia antigua de México bajo las pautas del racionalismo historiográfico del siglo dieciochesco, que se centraban, como bien lo señala CañizaresEsguerra, en un "nuevo arte de leer” las fuentes del pasado, con el fin de implantar una diferenciación entre lo irracional de la historiografía renacentista, la cual había glorificado en gran medida la hazaña española del descubrimiento y conquista de América, y la nueva lectura racional de esas mismas fuentes, privilegiando el cientificismo que acompañaba la nueva conciencia planetaria comandada por la Europa nórdica. Sin embargo, el jesuita criollo se diferencia de esta corriente historiográfica nordeuropea ya que convalida algunas de las fuentes renacentistas que los europeos ilustrados execraban por estar basadas en el testimonio ocular de gente que, según los filósofos modernos, no había sido entrenada para ello. Aun más, el criollo le da autoridad historiográfica a las fuentes indígenas que los europeos desacreditaban por considerar a las culturas amerindias incapaces de llevar un recuento de su historia por carecer de una escritura alfabética. Así, Clavijero busca esa verdad sobre el continente americano en el archivo criollo, de ahí que sea lo propio y no lo ajeno lo que iba a dar validez a su texto histórico, siempre tratando de encontrar ese punto medio que le diera objetividad a su historia y que el racionalismo ilustrado le obligaba a seguir:

Al referir los acontecimientos de la conquista que hicieron los españoles, me aparto igualmente del panegírico de Solís que de la invectiva del ilustrísimo señor Las Casas, porque no quiero adular a mis nacionales ni tampoco calumniarlos. Dejo los hechos en aquel grado de certeza o verosimilitud en que los encuentro. (xxii)

Su apego a la "verdad” hace que el jesuita en ningún momento intente hacer una simple exaltación de la historia de su país, pues su objetivo está centrado en desenterrar y exponer la producción intelectual mexicana a través de sus propios textos, a través de los cuales refuta los argumentos que los europeos esgrimían sobre el espacio americano, descrito como un continente vacío intelectualmente. La fuerte reacción que lo motivó a salir en defensa de la tierra que lo vio nacer no era para menos. No obstante, Clavijero evita mostrar sus emociones 
poniendo mucho cuidado en establecer su posición subjetiva en relación con el texto, y su aproximación al problema planteado, pues recalca que el origen de su obra fue llevado por la razón universal y el “celo por la humanidad”, y no por la "pasión o interés” que uno puede asumir al defender la patria, ya que las emociones tienden a desvirtuar el objetivo central del historiador, que es la búsqueda de la verdad, y en este caso, la verdad criolla.

Desde el inicio de la Historia antigua de México, el lector implícito es advertido de que la presente es "una historia de México escrita por un mexicano" en donde se va a "honrar la memoria de algunos ilustres americanos cuyas obras son totalmente desconocidas en Europa”, para así poder resarcir las imágenes del territorio novohispano que se había pintado como un "desierto literario". Clavijero aprovecha este espacio para resaltar su dominio del náhuatl, la lengua indígena del imperio mexicano, como una muestra de los niveles de su erudición enciclopédica. Esto convierte a esta lengua americana en una herramienta historiográfica muy importante, ya que es a través de ella como se puede acceder al legado histórico indígena, algo que pocos europeos poseían o conocían. Como prueba de ello, el jesuita indica que las pinturas jeroglíficas de los mexicanos habían sido las que "suministraron la mayor parte de los materiales para la historia antigua de México” de autores como Fernando de Alva Ixtlilxóchitl, pasando por Domingo Chimalpáin y Fernando de Alvarado Tezozómoc, hasta Fray Bernadino de Sahagún y Fray Juan de Torquemada (535). Todos estos autores representaban parte de la herencia cultural novohispana y, por extensión, de América, y su autoridad radicaba en el trabajo intelectual de haber rescatado y compilado el legado indígena que para estas fechas era parte imprescindible de la epistemología criolla, a la que pertenecía la propia narrativa de Clavijero. Es por eso que el propio jesuita novohispano se lamentará la "pérdida de aquella prodigiosa multitud de pinturas" (251), y aprovecha el medio para hacer un llamado a la comunidad imaginaria criolla para que "no se pierda lo que nos queda" (xviii).

La heterogeneidad étnica de estos escritores -indígenas, mestizos y españoles- nos habla de la forma en que el criollo visualiza a la nación mexicana, vinculado cada uno tanto por una confraternidad étnica como por los niveles e intereses intelectuales que existían entre ellos. De esta manera la imagen de nación del jesuita aparece móvil y flexible, representada por diversos miembros del espacio sociocultural del virreinato cuyo único requisito para pertenecer a él era haber contribuido al archivo cultural a través de su trabajo intelectual, propuesto como un servicio más amplio y de mayor envergadura: la patria criolla.

Para Clavijero, la ignorancia y los errores de los europeos se debía a que carecían de las herramientas y los conocimientos arriba señalados y, por tanto, no podían estar facultados para escribir sobre el pasado prehispánico, pues sólo los criollos, conocedores del náhuatl y de la historiografía indígena, tenían la autoridad para hacerlo. Esta posición subjetiva convierte a los intelectuales criollos en los herederos de la historiografía nativa, la cual consideraban ya como su propio pasado clásico, equivalente a la Grecia y Roma europea.

En su lucha por legitimar su conocimiento, Clavijero insiste en establecer el espacio que ocupa dentro de esa comunidad como un locus privilegiado y autorizado de la enunciación. Para el autor de la Historia antigua de México, el haber nacido en América le confiere una potestad sobre lo que escribe, debido a la experiencia empírica que había adquirido en el estudio de la naturaleza y su interacción con la población nativa. "Lo que 
yo diré -advierte el criollo- va fundado en sobre un serio y prolijo estudio de su historia, y sobre el íntimo trato [que tuve] de los mexicanos por muchos años”. El jesuita transforma esta experiencia nativa en autoridad para darle una mayor validez y veracidad a su obra, sobre todo con respecto a las que habían sido creadas desde los escritorios europeos por autores que por "la falta de conocimiento" de los mexicanos habían creado retratos distorsionados y poco fieles de ellos (45). De ahí que, como bien lo señala Jorge Cañizares-Esguerra, Clavijero reproche a los naturalistas europeos el interés que tenían en crear sistemas más que en la compilación de hechos basados en el conocimiento empírico (237).

Así, por ejemplo, para impugnar los señalamientos de De Pauw sobre la inferioridad del hombre americano, Clavijero los confronta con los comentarios de Antonio de Ulloa, el capitán español que había formado parte de la famosa expedición internacional de 1735 en América del Sur:

Paw presenta a los americanos débiles y enfermizos; Ulloa, por el contrario, afirma que son sanos, robustos y fuertes. ¿Quién de los dos merecerá de nosotros más crédito, Paw que desde Berlín se puso a filosofar sobre los americanos sin conocerlos, o Ulloa que por algunos años los vio y trató en diversos países de la América meridional? ¿Paw que tomó el empeño de vilipendiar y envilecernos por establecer su disparatado sistema de la degeneración, o Ulloa, que aunque, por otra parte, poco favorable a los indios, no trató de formar ningún sistema sino solamente escribir lo que juzgaba cierto? El lector imparcial decidirá. (506, énfasis mío)

Si como señala Luis Villoro, la Europa del siglo xviı había utilizado la razón como una pauta infalible y universal con la cual valoraba y medía todo, la crítica que Clavijero hace en el párrafo anterior era contundente ya que desarticulaba y reconstruía el criterio de verdad con el cual los europeos habían atribuido "a todos los americanos lo que se ha observado en algunos individuos o en ningunos" para luego hacer deducciones erróneas de ellas (508). El jesuita desarma el razonamiento de los europeos con la misma pauta racionalista dieciochesca, a través de una argumentación ad hominem, para poner entre dicho sus argumentos y calificarlos como meras “fábulas” y “niñerías” que los viajeros, historiadores, naturalistas y filósofos europeos habían pronunciado contra el continente americano. De esta manera, el criollo se transformaba de acusado a acusador, de juzgado a juez, volteándole la tortilla a la arrogante Europa que se atribuía el monopolio de la verdad (Villoro 116-118).

Con ese criterio universal de la razón, Clavijero niega el discurso planetario, que se pronunciaba contra América, como una verdad universal. Juzga a sus vociferantes interlocutores, y los confronta para luego desenmascarar y debilitar cada uno de los razonamientos con el fin de demostrar sus errores, que algunas veces aparecen como disparatadas "bufonadas", de las que se llega a mofar. El jesuita era consciente de que se estaba enfrentando modelos europeos con tendencias universales, cuyo fin era privilegiar el orden natural de las cosas ya clasificadas jerárquicamente por Europa. Para el novohispano las irregularidades que los naturalistas observaban en lo americano eran el resultado de una necedad arrogante de comparar las nueva especies con otras conocidas o, mejor dicho, contrastar las especies americanas con las categorías del Viejo Mundo, tomadas estas últimas como modelos ejemplares. 
Clavijero ofrece muchos ejemplos de la imposición que De Pauw o Buffon hacen del sistema taxonómico europeo para clasificar las especies americanas. Uno muy significado es el del suri o touyon, un ave americana de gran tamaño que fue llamada avestruz por De Pauw aunque era de una especie distinta a la africana. Para De Pauw, existía una "deformidad" o "irregularidad" en el touyon ya que tenía cuatro dedos separados, en vez de los dos dedos unidos por una membrana del avestruz. En un diálogo simulado entre un americano y De Pauw, el criollo novohispano objeta el que se tenga que tomar como modelo el ave africana, pues el tener sólo dos dedos unidos por una membrana implicaría, para un americano, una irregularidad en ésta, y no en los cuatro dedos del touyon. El De Pauw de Clavijero le responde al americano con un rotundo y enfático ¡no!, ya que "la irregularidad está en vuestros avestruces, porque no se conforman con los del Mundo Antiguo que son los ejemplares de la especie" (484, énfasis mío). Con esto Clavijero pone al descubierto la pelea en la que está enfrascado: la defensa de la taxonomía americana y la impugnación al uso de lo europeo como arquetipo universal, al cual se debían conformar todas las especies del mundo, y que el criollo ignora y se niega a aceptar.

El jesuita expone la taxonomía planetaria como una medida y valor, a la cual se le otorga el carácter de meta y objetivo a ser alcanzado. Desde el momento en que la norma europea es afirmada como un valor, la polaridad emerge casi de modo necesario; pues si algo es querido como un valor su contrario será rechazado como un no valor, es decir, una irregularidad. El criollo increpa al europeo por negarse a ver la diferencia en las especies americanas y aferrarse en aplicar su sistema de clasificación que acepta sólo su norma y, por tanto, no hace más que ver irregularidades y desproporciones -unos no valores- donde no los hay.

En cuanto al clima de la naturaleza americana se refiere, Clavijero desbarata fácilmente los señalamientos de De Pauw, Buffon y todos los que aseguraban que la naturaleza americana era inaccesible, fría y con llanuras anegadas, pantanosas y estériles, en donde las plantas y los árboles difícilmente daban frutos, y cuando los daban eran de una calidad muy inferior a la de los de Europa. Clavijero contesta que, si bien es cierto que en México, y en las otras regiones de América, existen lugares pantanosos y fríos, son más las tierras fértiles, de tal manera que mientras en "Europa no hay más que una siembra y una cosecha; en Nueva España hay varias” (469).

En su defensa de los indios, Clavijero trata de ser siempre fiel a la "verdad", sin condenar ni alabar, y más bien da razones y testimonios apegados al racionalismo del momento al cual él era un gran adepto. ${ }^{11}$ Sin embargo, no deja de asumir un carácter apologético cuando trata ciertos aspectos de la historia o cultura indígenas que, él sentía, eran relevantes para el objetivo de su obra. Es el caso de la educación que los indígenas recibían en su juventud, pues para el jesuita estas instrucciones eran dignas de admirar, ya que si bien estaban mezcladas con supersticiones, descartadas éstas últimas podrían "servir de lecciones a la nuestra" (201). Por otro lado, cuando habla de los aspectos negativos de los mexicanos, el jesuita muestra éstos no como rasgos intrínsecos de su carácter sino como resultado de las

${ }^{11}$ Clavijero fue uno de los impulsores de la reforma educativa en el virreinato de la Nueva España que buscaba promover el estudio de las ciencias exactas, el método experimental y la lectura de filósofos modernos como Descartes, Newton, Leibnitz y Bacon, entre otros. Fue nombrado prefecto de estudios del Colegio de San Idelfonso, del cual tuvo que renunciar pues las reformas que él planteaba no fueron apoyadas por el rector del colegio (Tanck de Estrada 43-45). 
condiciones y los contextos históricos a que todas las culturas están expuestas. Por tanto los indios son esencialmente iguales a los demás hombres, con los mismos dotes y facultades, pues "son capaces de todas las ciencias, como lo ha demostrado la experiencia” (46).

Si bien Clavijero intenta señalar la igualdad entre el indio y el europeo en cuanto a sus capacidades intelectuales y creativas, al mismo tiempo, advierte una diferencia en el primero, la cual nada tiene que ver con la inferioridad señalada por los filósofos modernos. Las características vistas en el cuerpo del indio determinadas como irregularidades, por ejemplo, la falta de vello, especialmente el facial, deben ser vistas, según el jesuita, como una particularidad del mexicano, tal y como las tienen otros pueblos o naciones. La diversidad de climas hacía posible la diversidad de seres vivientes y los seres humanos no eran la excepción. Pues, si bien algunos frutos o plantas prenden mejor en un lugar que en otro, esto no se debía a la superioridad o inferioridad del terreno, sino al hecho de que cada planta progresa mejor en el "temperamento que le conviene" (470).

A todo esto, Clavijero parece insertar aquí el otro objetivo de su obra, que sería la crítica al gobierno español. Para el jesuita, la degradación que uno podría ver en el indio no se debería entender, como ya se dijo, como una particularidad intrínseca, sino como el resultado de las condiciones históricas a las que había estado sometido durante siglos, en este caso, bajo el sistema colonial español. El jesuita tomó como ejemplo la adicción que los indígenas tenían al pulque, señalando que el régimen colonial los había llevado a una decadencia moral pues ahora más de la mitad de la población estaba sumergida en el vicio de la embriaguez, ya que en los tiempos antiguos "la severidad de las leyes los contenían en su beber" (45).

Así, la condición indigna en la que se encontraba los indios no era por la falta de aptitudes o capacidades, sino debido a la situación servil a la que se les había sujetado. Si se negaban a trabajar para los españoles, no era por la supuesta pereza que se les achaca, sino por los trabajos forzados que los europeos los habían obligado a ejercer, creando con ello un encono entre la población nativa. "Sin embargo-subraya Clavijero-no hay gente en aquel reino que trabaje más [que el indígena], ni cuyo trabajo sea más útil ni más necesario” (46; énfasis mío). El criollo parece ver en la población nativa a unos compatriotas maltratados y abandonados por el sistema colonial español, que solamente veía en ellos una mano de obra de la cual podía disponer, aun forzadamente, en el momento deseado. Para el jesuita, no hay posibilidad de prosperar ni salir adelante bajo esas condiciones, pues "es muy difícil, por no decir imposible, hacer progresos en las ciencias en medio de una vida miserable y servil y de continuas incomodidades” a las que se sometía al indígena (518).

Esto era una clara condena al gobierno español, pues el jesuita lo acusaba de haber empujado a la miseria a una parte importante del cuerpo social novohispano, a aquellos a quienes los criollos habían arrebatado su legado cultural para poder apropiárselo en su intento por crearse una conciencia e identidad americanas. Pareciera que Clavijero estaba pagando con esta defensa esa deuda moral que la sociedad criolla tenía con la población nativa. Como buen educador jesuita, ve el remedio para aliviar el estado del indígena a través de la educación, pues como él mismo señala, “lo malo podría en la mayor parte corregirse con la educación, como lo ha mostrado la experiencia.” Curiosamente esa experiencia de la que él habla había sido acumulada por "muchos hábiles criollos” que fungieron como maestros de "los pocos mexicanos que se han dedicado al estudio de las letras, por estar el común de la nación empleado en trabajos públicos o privados”. La degradación indígena, 
por tanto, no era por el clima, como clamaban los europeos, sino porque el estado español los había arruinado y no había procurado un bienestar para esa población:

Por lo demás no puede dudarse que los mexicanos presentes no son en todo semejantes a los antiguos, como no son semejantes los griegos modernos a los que existieron en tiempos de Platón y de Pericles. La constitución política y religiosa de un Estado, tiene demasiado influjo en los ánimos de una nación. (46-47)

La critica contra el sistema colonial está claramente delineada en el párrafo anterior. Y por obvias razones, Clavijero se identifica aquí más con el indígena que con el español, pues parece inferir una analogía entre la situación subordinada del indígena bajo el gobierno español, y la de los criollos con las reformas borbónicas. El estado español es visto aquí más como una tiranía que como la madre patria, la cual debía procurar acoger y cobijar a sus hijos. ¿No es ésta precisamente la queja de los criollos? ¿Estaría acaso Clavijero proponiendo que la salvación del indígena estaba sólo en las manos de una nación criolla? ¿Hasta qué punto el conocimiento de la cultura e historiografía mexicana le iban a servir al criollo para reivindicar al indio como ciudadano de la nación criolla? Estas son algunas preguntas que con el tiempo vendrían a darse entre la élite intelectual criolla, una vez que el sueño político de esta clase social se convirtiera en realidad con los movimientos independentistas del siglo posterior.

Fue así como el siglo xvin significó, para el continente americano, un periodo de reinvenciones y de reconquistas disputadas en varios bandos. Por un lado estaban las instancias del poder europeo que procuraban establecer sus proyectos expansionistas a través de reformas políticas y producciones discursivas cuya finalidad era buscar un mayor control sobre los territorios del Nuevo Mundo y obtener así los mayores beneficios posibles. Mientras que, en cambio, los grupos intelectuales criollos que, viendo amenazados sus intereses e ideales nacionales con los embates reformista españoles por un lado y la conciencia planetaria del cientificismo europeo por otro, crean un discurso alternativo para confrontarlo a la embestida europea, al mismo tiempo que construyen las bases epistemológicas de su proyecto de nación.

La posición epistemológica criolla del dieciocho revalida la historiografía del Nuevo Mundo, que era negada por Europa, y la propone como la única válida, con lo cual se realizaba la reinvención y reconquista criolla de los territorios americanos. Con la ayuda del archivo criollo citado en su obra, el jesuita novohispano crea una imagen propia de México y de América, totalmente distinta a las emanadas de los textos provenientes de los centros hegemónicos europeos. Para Clavijero, el Nuevo Mundo no es tan nuevo como los europeos lo habían estado señalándo. Y para demostrarlo rescata el pasado indígena como una muestra de la historia intelectual de la nación mexicana. Con el rescate del indígena, el criollo se rescata a sí mismo, y junto con él su proyecto de nación. Pues es precisamente la historia mexicana la que funda y establece las raíces americanas de la nación criolla, jugando el papel de una historia clásica americana que la Europa ilustrada quería negarle.

Francisco Javier Clavijero rechaza tajantemente ese "nuevo arte de leer” las fuentes historiográficas que los nordeuropeos proponían como el correcto. El criollo cree imprescindible la defensa del indígena, pues a través de ésta, la nación criolla podía liberarse 
de ese discurso reduccionista y colonial que estaban emprendiendo las naciones europeas con su proyecto planetario de reconquista de América. El jesuita ve la situación degradada del indígena no como algo intrínseco o congénito, sino como un resultado de siglos de sumisión y explotación a que había estado sometido bajo el sistema colonial español. Esta era una clara crítica al gobierno español, y el jesuita no pierde la oportunidad de expresarla en su obra. La labor de Clavijero no fue nada fácil, pues se enfrentaba ante un discurso que se establecía como moderno y científico y era respaldado por el poder económico y militar de esas naciones que lo promovían. Sin embargo el jesuita criollo pudo encontrar debilidades en los textos de escritores como Buffon y De Pauw, utilizando la propia razón como arma retórica que el propio cientificismo del momento promovía, para hacer su propia reconquista de América. Sólo por medio del racionalismo ilustrado se podía convalidar y restaurar la imagen criolla de América, con la cual se establecían los cimientos que apoyarían lo que vendría a ser la futura nación mexicana.

\section{BiBLIOGRAFÍA}

Ainsa, Fernando. De la Edad de Oro a El Dorado. México: FCE, 1992.

Blunt, Wilfrid. The Complete Naturalist: A Life of Linnaeus. Londres: William Collins \& Co., 1971.

Brading, David. The First America. Cambridge: Cambridge UP, 1991.

Cañizares-Esguerra, Jorge. How to Write the History of the New World. Histories, Epistemologies, and Identities in the Eighteenth-Century Atlantic World. Stanford: Stanford UP, 2001.

Clavijero, Francisco Javier. Historia antigua de México. México: Porrúa, 1964.

Elias, Norbert. The Civilizing Process. The Development of Manners. Nueva York: Urizen Books, 1978.

Florescano, Enrique e Isabel Gil Sánchez. "La época de las reformas borbónicas y el crecimiento económico”. Historia general de México. Vol. I. México: El Colegio de México, 1987.

Gerbi, Antonello. The Dispute of the New World. The History of a Polemic. Jeremy Moyle, ed. y trad. Pittsburgh: U of Pittsburgh P, 1973.

Hardy, Charles. The Negro Question in the French Revolution. Menasha, WI: George Banta Publishing Co., 1919.

Higgins, Antony. Constructing the "Criollo" Archive. Subjects of Knowledge in the "Bibliotheca Mexicana" and the "Rusticatio Mexicana". West Lafayette, IN: Purdue UP, 2000.

Fabian, Johannes. Time and the Other: How Anthropology Makes its Object. Nueva York: Columbia UP, 1983.

Miranda, José y Pablo González Casanova. Sátira anónima del siglo XVIII. México: FCE, 1953.

Noreña, Carlos. Studies in Spanish Renaissance Thought. La Haya: Martinus Nijhoff, 1975.

O’Gorman, Edmundo. Destierro de sombras. Luz en el origen de la imagen y culto de nuestra señora de Guadalupe del Tepeyac. México: UNAM, 1986. 
Pratt, Mary Louise. Imperial Eyes. Travel Writing and Transculturation. Londres y Nueva York: Routledge, 1992.

Rivera-Ayala, Sergio. “Dance of the People: The Chuchumbé”. Colonial Lives: Documents on Latin American History 1550-1850. Richard E. Boyer y Geoffrey Spurling, eds. Nueva York: Oxford UP, 2000.

Espacio, cuerpo y poder: estrategias del discurso colonial en textos novohispanos. University Press of America, en prensa (2007).

San Juan, Huarte de. Examen de ingenios para las ciencias. Guillermo Serés, ed. Madrid: Cátedra, 1989.

Schiebinger, Londa. Nature's Body. Gender in the Making of Modern Science. Boston: Beacon Press, 1993.

Tanck de Estrada, Dorothy. “Tensión en la torre de marfil”. Ensayos sobre la educación en México. México: El Colegio de México, 1981. 48-56.

Villoro, Luis. Los grandes momentos del indigenismo en México. México: FCE, 1996.

Zantop, Suzanne. "Dialectics and Colonialism: The Underside of the Enlightenment". Impure Reason. Dialectic of Enlightenment in Germany. W. Daniel Wilson y Robert C. Holub, eds. Detroit: Wayne State UP, 1993. 